\title{
Expression of CLDN1 in colorectal cancer: A novel marker for prognosis
}

\author{
SUMIKO NAKAGAWA ${ }^{1}$, NORIKATSU MIYOSHI ${ }^{1}$, HIDESHI ISHII $^{1}$, KOSHI MIMORI $^{2}$, \\ FUMIAKI TANAKA $^{2}$, MITSUGU SEKIMOTO ${ }^{1}$, YUICHIRO DOKI ${ }^{1}$ and MASAKI MORI ${ }^{1}$ \\ ${ }^{1}$ Department of Gastroenterological Surgery, Osaka University Graduate School of Medicine, Suita, Yamadaoka 2-2, \\ Osaka 565-0871; ${ }^{2}$ Department of Molecular and Cellular Biology, Division of Molecular and Surgical Oncology, \\ Kyushu University, Medical Institute of Bioregulation, Tsurumihara 4546, Beppu, Ohita 874-0838, Japan
}

Received February 15, 2011; Accepted April 19, 2011

DOI: 10.3892/ijo.2011.1102

\begin{abstract}
Claudin1 (CLDNI) plays an important role not only in the intercellular barrier function of tight junctions (TJs) but also in migration and invasiveness of cancer cells. Previous reports show that $C L D N 1$ overexpression is significantly related to the malignant behavior in several cancer types whereas its significance in colorectal cancer (CRC) is not fully understood. The present study comprised 119 patients who underwent surgery for CRC, as well as 3 cell lines derived from human CRC. The correlation of gene expression with clinical parameters in patients was assessed by knockdown experiments using 3 cell lines. Patients with high CLDN1 expression were statistically shown to have a relatively better prognosis, and those with low $C L D N 1$ expression showed poorer overall survival and disease-free survival than those with high expression. The assessment of CLDN1 knockdown in the 3 cell lines demonstrated that the siRNA inhibition resulted in a statistically significant increase in cell invasiveness. In conclusion, the present data strongly suggest that $C L D N 1$ expression is a prognostic factor in CRC patients.
\end{abstract}

\section{Introduction}

Many developed countries including the United States and Japan have an aging population, where cancer is one of the most prominent illnesses, in terms of public welfare and health measures. For example, one in four deaths in the United States is due to cancer (1). In the United States, the incidence of CRC has increased significantly in recent years, in concert with the changing lifestyle (2), and CRC is one of the most prominent causes of death from neoplastic disease in Japan (2). The major cause of death in CRC is due to distant metastases (3). Identification of genes responsible for the development and progression of CRC and comprehension of

Correspondence to: Dr Masaki Mori, Yamadaoka, Suita 2-2, Osaka 565-0871, Japan

E-mail: mmori@gesurg.med.osaka-u.ac.jp

Key words: claudin1, prognosis, colorectal cancer the clinical significance are critical for the diagnosis and adequate treatment of the disease. Characterization of the key molecules is particularly promising for the development of novel approaches to the treatment of gastrointestinal tumors.

The claudin $(C L D N)$ family were first discovered in 1998, and the $C L D N$ family consists of at least 24 members, the expression of which depends on cell type and tissue $(4,5)$. $C L D N$ s encode proteins with 4 taransmembrane domains, and the $\mathrm{C}$-terminal domain serves as a binding site for interaction with a complex set of proteins including site for PDZ domain proteins that are involved in intracellular signaling (6-8). Recent reports showed that $C L D N$ gene expression is frequently altered in several cancer types, and the members of $C L D N$ family are reported as up- or down-regulated according to the organ $(9,10)$.

The aim of this study was to analyze the correlation between the expressions of CLDN1 in CRC tissues from patients with clinicopathological factors and to investigate its possible functions in tumorigenesis and metastasis in CRC.

\section{Materials and methods}

Clinical tissue samples. One hundred and nineteen patients (74 men, 45 women) with CRC were registered and underwent curative surgery including distant metastasis at the Medical Institute of Bioregulation at Kyusyu University from 1993 to 2001. None of the patients received chemotherapy or radiotherapy prior to surgery. Primary CRC specimens and adjacent normal colorectal mucosa were obtained from patients after written, informed consent had been confirmed, in accordance with the institutional ethical guidelines. The surgical specimens were fixed in formalin, processed through graded ethanol, and embedded in paraffin. The sections were stained with hematoxylin and eosin, and Elastica van Gieson stain, and the degree of histological differentiation, lymphatic invasion and venous invasion was examined. The samples of all specimens were also frozen in liquid nitrogen immediately after resection and kept at $-80^{\circ} \mathrm{C}$ until RNA extractions. None of the patients received chemotherapy or radiotherapy prior to surgery. After surgery, the patients were followed up with a blood examination including the tumor markers serum carcinoembryonic antigen (CEA) and cancer antigen (CA19-9), 
and imaging modalities such as abdominal ultrasonography, computed tomography, and chest X-ray every 3-6 months. Postoperatively, stage III and IV patients received 5 -fluorouracil-based chemotherapy, whereas stage I and II patients principally received no chemo-therapy. All these therapies were performed according to the Japanese guidelines (11). Clinico-pathological factors were assessed according to the tumor node metastasis (TNM) classi-fication of the International Union Against Cancer (UICC) (12).

Cell lines and culture. Three cell lines derived from human colorectal cancer (DLD-1, HCT116 and LoVo) (13-15) were obtained and maintained in Dulbecco's modified Eagle's medium (DMEM) containing 10\% fetal bovine serum and antibiotics at $37^{\circ} \mathrm{C}$ in a $5 \%$ humidified $\mathrm{CO}_{2}$ atmosphere. For siRNA inhibition, double-stranded RNA duplexes targeting human $C L D N 1$ were purchased from Invitrogen as Stealth RNAi (HSS113420, HSS189840, HSS189841; Invitrogen, Carlsbad, CA, USA). For comparison, a negative control siRNA (NC) was also purchased from Invitrogen. CRC cell lines were transfected with siRNA at a concentration of $20 \mu \mathrm{mol} / 1$ using lipofectamine RNAiMAX (Invitrogen), incubated in glucose-free Opti-MEM (Invitrogen) for the time indicated, and analyzed using a proliferation and invasion assay after $48 \mathrm{~h}$. All siRNA duplexes were used together in a triple transfection. A significant reduction in CLDNI by siRNA was confirmed by quantitative real-time RT-PCR. The growth rate of the cultured CRC cell lines was measured by counting cells using CellTac (Nihonkoden, Tokyo, Japan). Each cell line with siRNA was compared to the wild-type and a negative control (NC). Values were expressed as standard error of mean (SEM) at least 3 independent experiments.

RNA preparation and expression analysis. Total RNA was prepared with DNase by a modified acid guanidium-phenolchoroform procedure (16). Reverse transcription was performed with $2.5 \mu \mathrm{g}$ of total RNA as described previously (17). A 155-bp $C L D N 1$ fragment was amplified. Two human $C L D N 1$ oligonucleotide primers for the PCR reaction were designed as follows: 5'-CCCTATGACCCCAGTCAATG-3' (forward); 5'-GTTTTGGATAGGGCCTTGGT-3' (reverse). The forward primer is located in exon 3 and the reverse primer in exon 4 . A PCR Kit (Takara, Kyoto, Japan) on a GeneAMP PCR System 9600 (PE Applied Biosystems, Foster City, CA, USA) was used to perform 35 cycles of PCR reaction with the following parameters: $95^{\circ} \mathrm{C}$ for $40 \mathrm{sec}, 45^{\circ} \mathrm{C}$ for $40 \mathrm{sec}$, and $72^{\circ} \mathrm{C}$ for $60 \mathrm{sec}$. An $8-\mu \mathrm{l}$ aliquot of each reaction mixture was sizefractionated in a $1.5 \%$ agarose gel and visualized with ethidium bromide staining. To ensure that the RNA was not degraded, a PCR assay with primers specific for the glyceraldehydes-3phosphate dehydrogenase $(G A P D H)$ gene was performed for $1 \mathrm{~min}$ at $95^{\circ} \mathrm{C}, 1 \mathrm{~min}$ at $56^{\circ} \mathrm{C}$, and $1 \mathrm{~min}$ at $72^{\circ} \mathrm{C}$ for 30 cycles. The GAPDH primers 5'-TTGGTATCGTGGAAGGACTCA-3' (forward) and 5'-TGTCATCATATTGGCAGGTT-3' (reverse) produced a 270-bp amplicon. Complimentary DNA from the Human Reference total RNA (Clontech, Palo Alto, CA, USA) was studied concurrently as a source of positive controls. For quantitative assessment, real-time quantitative reverse transcriptase (RT)-PCR was performed using a LightCycler FastStart DNA Master SYBR-Green I kit (Roche Diagnostics,

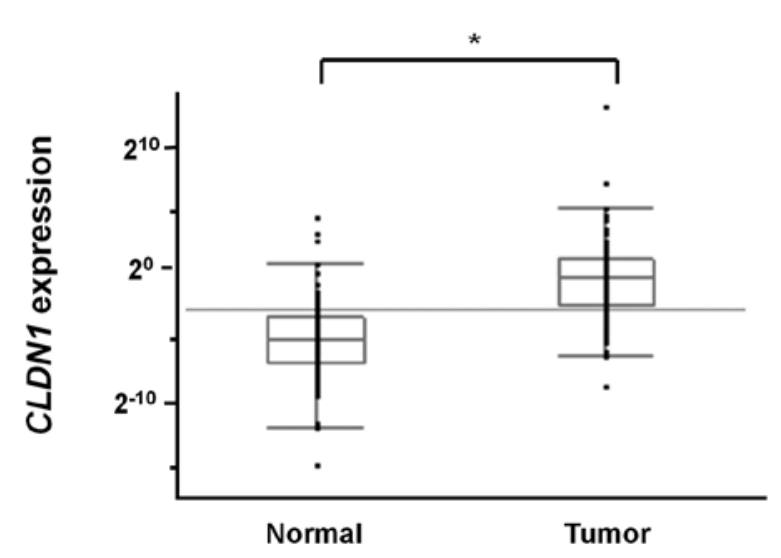

Figure 1. CLDN1 expression in clinical tissue specimens. Quantitative realtime RT-PCR on 119 paired clinical samples showed the relative expressions of CLDN1 mRNA in tumors and paired normal tissues (normalized by GAPDH mRNA expression) ("p<0.001).

Tokyo, Japan) for cDNA amplification of CLDN1 and GAPDH. The amplification protocol consisted of 35 cycles of denaturation at $95^{\circ} \mathrm{C}$ for $10 \mathrm{sec}$, annealing at $60^{\circ} \mathrm{C}$ for $10 \mathrm{sec}$, and elongation at $72^{\circ} \mathrm{C}$ for $10 \mathrm{sec}$. The products were then subjected to a temperature gradient from 55 to $95^{\circ} \mathrm{C}$ with continuous fluorescence monitoring to produce a melting curve of the products. The expression ratios of $C L D N 1$ mRNA copies in tumor and normal tissues were calculated, normalized against GAPDH mRNA expression.

Invasion assays. Cell invasion were assessed with CytoSelect Cell Invasion Assay according to the protocol of the manufacturer (Cell Biolabs, San Diego, CA) after $48 \mathrm{~h}$ of the transfection. Cells in DMEM $\left(1.0 \times 10^{5}\right)$ were placed on each $8.0-\mu \mathrm{m}$ pore size membrane insert in 96-well plates. DMEM with $10 \%$ FBS was placed in the bottom wells. After $24 \mathrm{~h}$, cells that did not invade were removed from the top side of the membrane chamber and completely dislodge the cells from the underside of the membrane by tilting the membrane chamber in the Cell Detachment Solution (Cell Biolabs). Lysis Buffer/CyQuannt GR dye solution (Cell Biolabs) was added to each well, the fluorescence of the mixture was read with a fluorescence plate reader at $480 / 520 \mathrm{~nm}$. The values were expressed as a ratio with wild-type (every parental cell).

Statistical analysis. The relationship between CLDN1 expression and clinico-pathological factors was analyzed with the Chi-square test. Kaplan-Meier survival curves were plotted and compared with the generalized log-rank test. Univariate and multivariate analyses to identify prognostic factors were performed using a Cox proportional hazard regression model. The values in vitro assays were analysed with Wilcoxon rank test. All tests were analyzed with JMP software (SAS Institute, Cary, NC, USA). $\mathrm{p}<0.05$ was considered statistically significant.

\section{Results}

Expression of CLDN1 in clinical tissue specimens and clinicopathological characteristics. We performed quantitative real-time RT-PCR analysis with primary CRC and adjacent 
Table I. Clinicopathological factors and CLDN1 mRNA expression in 119 CRC.

\begin{tabular}{|c|c|c|c|}
\hline Factors & $\begin{array}{l}\text { High expression } \\
n=59(\%)\end{array}$ & $\begin{array}{l}\text { Low expression } \\
n=60(\%)\end{array}$ & p-value \\
\hline \multicolumn{4}{|l|}{ Age } \\
\hline$<68$ & $27(45.7)$ & $30(50.0)$ & \multirow[t]{2}{*}{0.643} \\
\hline$\geq 68$ & $32(54.2)$ & $30(50.0)$ & \\
\hline \multicolumn{4}{|l|}{ Gender } \\
\hline Female & $26(44.1)$ & $19(31.7)$ & \multirow[t]{2}{*}{0.163} \\
\hline Male & $33(55.9)$ & $41(68.3)$ & \\
\hline \multicolumn{4}{|c|}{ Histological grade } \\
\hline Others & $5 \quad(8.5)$ & $4 \quad(6.7)$ & \multirow[t]{2}{*}{0.709} \\
\hline Wel/mod. & $54(91.5)$ & $56(93.3)$ & \\
\hline \multicolumn{4}{|l|}{ Tumor type } \\
\hline $0-1$ & $5 \quad(8.5)$ & $11(18.3)$ & \multirow[t]{2}{*}{0.115} \\
\hline $2-4$ & $54(91.5)$ & $49(81.7)$ & \\
\hline \multicolumn{4}{|l|}{ Tumor size } \\
\hline$<30 \mathrm{~mm}$ & $49(83.1)$ & $49(81.7)$ & \multirow[t]{2}{*}{0.843} \\
\hline$\geq 30 \mathrm{~mm}$ & $10(16.9)$ & $11(18.3)$ & \\
\hline \multicolumn{4}{|l|}{ Depth } \\
\hline $3<\mathrm{T}$ & $51(86.4)$ & $42(70.0)$ & \multirow[t]{2}{*}{$\underline{0.030}$} \\
\hline $\mathrm{T}<2$ & $8(13.6)$ & $18(30.0)$ & \\
\hline \multicolumn{4}{|c|}{ Lymph node metastasis } \\
\hline Absent & $34(57.6)$ & $30(50.0)$ & \multirow[t]{2}{*}{0.404} \\
\hline Present & $25(42.4)$ & $30(50.0)$ & \\
\hline \multicolumn{4}{|c|}{ Lymphatic invasion } \\
\hline Absent & $34(57.6)$ & $36(60.0)$ & \multirow[t]{2}{*}{0.793} \\
\hline Present & $25(42.4)$ & $24(40.0)$ & \\
\hline \multicolumn{4}{|c|}{ Venous invasion } \\
\hline Absent & $49(83.1)$ & $46(76.7)$ & \multirow[t]{2}{*}{0.386} \\
\hline Present & $10(16.9)$ & $14(23.3)$ & \\
\hline \multicolumn{4}{|c|}{ Monochronous metastasis (UICC) } \\
\hline Absent & $43(72.9)$ & $38(63.3)$ & \multirow[t]{2}{*}{0.264} \\
\hline Present & $16(27.1)$ & $22(36.7)$ & \\
\hline
\end{tabular}

Wel, well differentiated adenocarcinoma; Mod, moderately differentiated adenocarcinoma; Others, poorly differentiated adenocarcinoma and mucinous carcinoma.

normal colorectal regions (Fig. 1). CLDN1 expression was calculated by $C L D N 1 / G A P D H$ expression. For the clinicopathological evaluation, experimental samples were divided into two groups according to the expression status. Patients with values more than the median $C L D N 1$ expression value (median, 0.700) were assigned to the high-expression group and the others were assigned to the low-expression group. Clinico-pathological factors related to CLDN1 expression status of the 119 patients are summarized in Table I. The data indicated that CLDN1 expression was correlated with tumor invasion $(\mathrm{p}=0.030)$. Other factors were not significantly correlated with CLDN1 expression.

Relationship between CLDN1 expression and prognosis. The data showed that the post-operative overall survival rate was significantly higher in patients in the high-expression group than the low-expression group $(\mathrm{p}=0.024)$ (Fig. 2). The median follow-up was 3.9 years. The disease-free survival rate after curative surgery except for cases with monochronous metastasis was higher in the high-expression group than the low-expression group (Fig. 3). Table II shows the results of the univariate and multivariate analyses for factors related to overall survival. The univariate analysis showed that grade of differentiation $(\mathrm{p}=0.045)$, morphological type $(\mathrm{p}=0.030)$, tumor size $(\mathrm{p}=0.005)$, tumor invasion $(\mathrm{p}<0.001)$, lymph node metastasis $(\mathrm{p}<0.001)$, lymphatic invasion $(\mathrm{p}<0.001)$, venous invasion $(\mathrm{p}<0.001)$ and metastasis $(\mathrm{p}<0.001)$ and CLDN1 expression $(\mathrm{p}=0.025)$ were significantly correlated with overall survival. The multivariate regression analysis indicated that CLDN1 high-expression group (relative risk, 


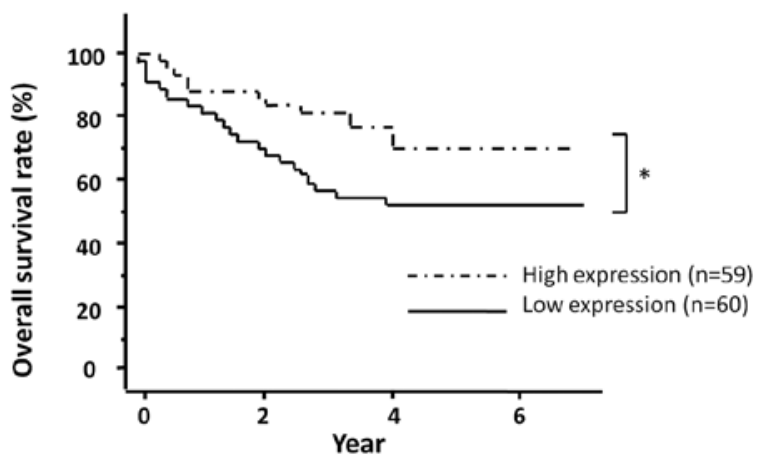

Figure 2. Overall survival rates of patients with CRC based on CLDN1 mRNA expression status. The overall survival rate was higher in the $C L D N 1$ high-expression group than the low-expression group ( $\mathrm{p}=0.024)$. $C L D N 1$ expression in tumor normalized by GAPDH mRNA expression is presented as relative expression to the paired normal colorectal mucosa.

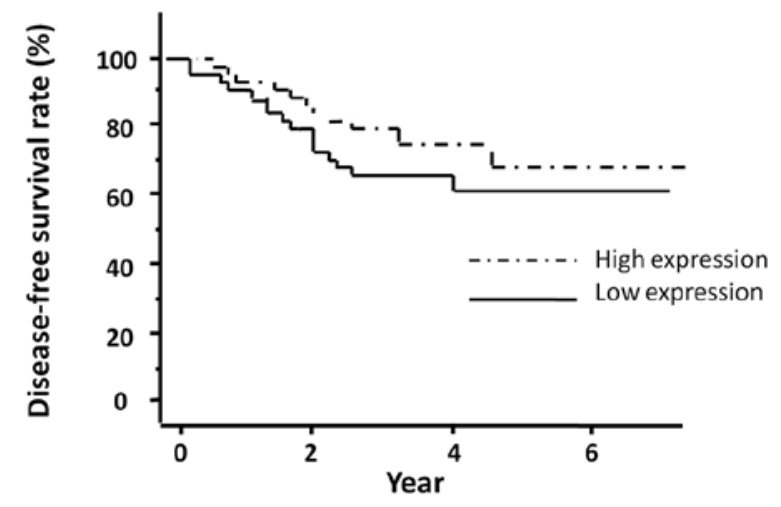

Figure 3. Disease-free survival rates of patients with CRC based on CLDN1 mRNA expression status. The disease-free survival rate was higher in the $C L D N 1$ high-expression group than the low-expression group $(\mathrm{p}=0.246)$. $C L D N 1$ expression in tumor was normalized by GAPDH mRNA expression.

Table II. Univariate and multivariate analyses for overall survival (Cox proportional hazards regression model).

\begin{tabular}{|c|c|c|c|c|c|c|}
\hline \multirow[b]{2}{*}{ Factors } & \multicolumn{2}{|c|}{ Univariate analysis } & \multirow[b]{2}{*}{ p-value } & \multicolumn{2}{|c|}{ Multivariate analysis } & \multirow[b]{2}{*}{ p-value } \\
\hline & $\mathrm{RR}$ & $95 \% \mathrm{CI}$ & & $\mathrm{RR}$ & $95 \% \mathrm{CI}$ & \\
\hline \multicolumn{7}{|l|}{ Age } \\
\hline$(<68 / \geq 68)$ & 1.58 & $0.83-3.08$ & 0.159 & & & \\
\hline \multicolumn{7}{|l|}{ Gender } \\
\hline (Male/female) & 1.48 & $0.76-3.03$ & 0.245 & & & \\
\hline \multicolumn{7}{|l|}{ Histological grade } \\
\hline (Others/wel-mod) & 1.73 & $1.01-2.67$ & $\underline{0.045}$ & 1.64 & $0.93-2.66$ & 0.082 \\
\hline \multicolumn{7}{|l|}{ Tumor type } \\
\hline$(2-4 / 0-1)$ & 3.64 & $1.10-22.39$ & $\underline{0.038}$ & 0.78 & $0.18-5.50$ & 0.774 \\
\hline \multicolumn{7}{|l|}{ Tumor size } \\
\hline$(\geq 30 /<30)$ & 2.19 & $1.21-5.44$ & $\underline{0.005}$ & 1.08 & $0.56-2.79$ & 0.839 \\
\hline \multicolumn{7}{|l|}{ Depth } \\
\hline$(3<\mathrm{T} / \mathrm{T}<2)$ & 3.73 & $1.73-15.72$ & $\leq 0.001$ & 2.38 & $0.90-11.19$ & 0.085 \\
\hline \multicolumn{7}{|l|}{ Lymph node metastasis } \\
\hline (Present/absent) & 4.28 & $2.15-9.27$ & $\leq 0.001$ & 1.39 & $0.63-3.30$ & 0.420 \\
\hline $\begin{array}{l}\text { Lymphatic invasion } \\
\text { (Present/absent) }\end{array}$ & 2.97 & $1.57-5.75$ & $\leq 0.001$ & 1.48 & $0.73-3.07$ & 0.277 \\
\hline \multicolumn{7}{|l|}{ Venous invasion } \\
\hline \multicolumn{7}{|l|}{ Metastasis(UICC) } \\
\hline \multicolumn{7}{|l|}{$C L D N 1$ expression } \\
\hline (Low/high) & 2.09 & $1.09-4.20$ & $\underline{0.025}$ & 1.99 & $1.01-4.12$ & $\underline{0.046}$ \\
\hline
\end{tabular}

Statistically significant values are underlined. RR, relative risk; CI, confidence interval; Wel, well differentiated adenocarcinoma; Mod, moderately differentiated adenocarcinoma; Others, poorly differentiated adenocarcinoma and mucinous carcinoma.

1.99; 95\% confidence interval, 1.01-4.12; $\mathrm{p}=0.046)$ and metastasis (relative risk, 5.46; 95\% confidence interval, $2.42-13.14 ; \mathrm{p}<0.001)$ were independent predictors of overall survival.
In vitro assessment of CLDN1 expression knockdown. Three $\mathrm{CRC}$ cell lines were chosen for the proliferation and invasion study. In these cell lines, CLDN1 expression correlated comparatively in clinical samples. The proliferation study was 

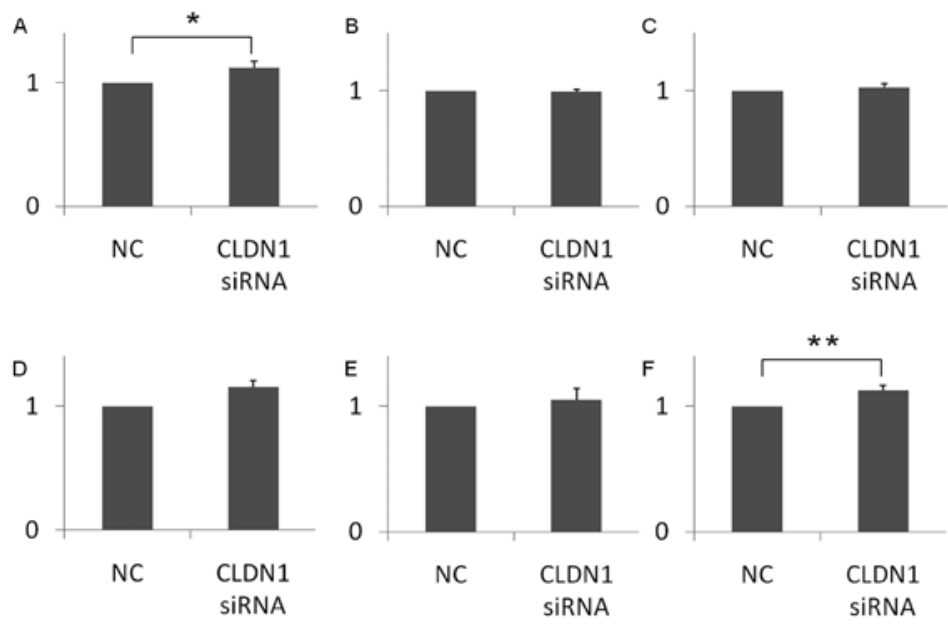

Figure 4. In vitro assays with siRNA inhibition in the 3 CRC cell lines. Proliferation assays were performed in 3 CRC cell lines (A, DLD-1; B, HCT116; C, LoVo). There was significant differences between NC and CLDN1 siRNA in DLD-1 ( $\left.\mathrm{n}=3,{ }^{*} \mathrm{p}<0.01\right)$. These assays showed differences in the ratio with control (with no treatment). Invasion assays were also performed in them (D, DLD-1; E, HCT116; F, LoVo). There was significant differences between NC and CLDN1 siRNA in LoVo $\left(n=5,{ }^{* *} \mathrm{p}<0.01\right)$. Invasion assays showed differences in the ratio with wild-type (every parental cell). Values are means and SEM. NC, negative control.

confirmed by seeding the cells $\left(1.0 \times 10^{5}\right)$ in 6 -well dishes and culturing them for $48 \mathrm{~h}$ to determine the cell growth. The results showed significant differences in DLD-1 cell numbers between NC and CLDN1 siRNA (n=3, p<0.05, Fig. 4A-C). In the invasion study, the results showed differences between $\mathrm{NC}$ and CLDN1 siRNA (Fig. 4D-F) including statistical significance in $\operatorname{LoVo}(n=5, p<0.01)$.

\section{Discussion}

Regarding the function of Tjs, there are reports on the maintenance of normal epithelium $(4,5,18,19)$. Their role in the neoplastic process, it is also important because of their reported malignant behavior (20). The role of CLDN in cancer has not been clearly defined, the expression of which are different in various organs (21-24). CLDN1 is a capital component of $\mathrm{Tj}$ s and reported to be necessary for $\mathrm{Tj}$ formation (25-27). However, the biological analysis is still to be performed.

The present study showed that CLDN1 expression is an independent prognostic factor for CRC. The siRNA inhibition experiment in the CRC cell lines demonstrated the functional relevance of $C L D N 1$. It suggests that the tumor malignancy correlates with CLDN1 expression and it might affect the values of other prognostic factors in multivariate analysis such as distant metastasis which was significant in univariate analysis. CLDN1 expression correlated with tumor invasiveness and was a significant prognostic factor similarly to distant metastasis. To the best of our knowledge, the present study is the first report to show CLDN1 as a statistically significant predictive marker for CRC prognosis after curative resection, such as other well-known important predictors (28). Furthermore, the results indicated $C L D N 1$ plays a role as tumor suppressor, supported by a functional relevance to cell invasiveness. According to previous reports, our results suggest that CLDN1-dependent pathway might be involved in the suppression of CRC, which vary among tissue types, such as skin, breast, liver and prostate $(22-24,29,30)$.
CLDN1 is useful to determine the necessity for intensive follow-up and adjuvant $\mathrm{CRC}$ therapy by predicting recurrence and metastases after curative surgical resection (31-33). In the present study, the clinico-pathological analysis revealed that CRC patients with high expression of CLDN1 showed a better prognosis for overall and disease-free survival than the lowexpression group. The data indicate that $C L D N 1$ is a presumptive novel predictor of CRC prognosis, especially relating to tumor invasiveness. Furthermore, it may be a therapeutic target in $\mathrm{CRC}$ based on the results from biological experiment in which CRC cell lines showed lower proliferation and invasiveness than those transfected with siRNA.

Several adjuvant chemotherapies are helpful in certain disease stages, especially in $\mathrm{CRC}$, and indicate the usefulness of less invasive surgery for CRC (28,31-40). For these cases, an informative prognostic marker, which is independent of traditional TNM classification and contributes to diagnoses and treatments, is very important. The present data indicate the candidacy of CLDN1. While improved preoperative and postoperative treatments, such as chemotherapy and radiotherapy combined with surgery for $\mathrm{CRC}$, have contributed to the reduction of recurrences, eventually half of the cases metastasize despite systemic chemotherapy followed by surgery (41). Adjuvant chemotherapy for CRC is desirable in highly suspicious recurrent cases. In these cases, CLDN1 analysis may be useful to predict and treat patients with a poor prognosis.

\section{References}

1. Jemal A, Siegel R, Xu J and Ward E: Cancer statistics, 2010. CA Cancer J Clin 60: 277-300, 2010.

2. Kohno SI, Luo C, Nawa A, et al: Oncolytic virotherapy with an HSV amplicon vector expressing granulocyte-macrophage colony-stimulating factor using the replication-competent HSV type 1 mutant HF10 as a helper virus. Cancer Gene Ther 14: 918-926, 2007.

3. Yamasaki M, Takemasa I, Komori T, et al: The gene expression profile represents the molecular nature of liver metastasis in colorectal cancer. Int J Oncol 30: 129-138, 2007. 
4. Tsukita S, Furuse M and Itoh M: Multifunctional strands in tight junctions. Nat Rev Mol Cell Biol 2: 285-293, 2001.

5. Morita K, Furuse M, Fujimoto K and Tsukita S: Claudin multigene family encoding four-transmembrane domain protein components of tight junction strands. Proc Natl Acad Sci USA 96: 511-516, 1999

6. Itoh M, Furuse M, Morita K, et al: Direct binding of three tight junction-associated MAGUKs, ZO-1, ZO-2, and ZO-3, with the COOH termini of claudins. J Cell Biol 147: 1351-1363, 1999.

7. Hamazaki Y, Itoh M, Sasaki H, et al: Multi-PDZ domain protein 1 (MUPP1) is concentrated at tight junctions through its possible interaction with claudin-1 and junctional adhesion molecule. J Biol Chem 277: 455-461, 2002.

8. Dhawan P, Singh AB, Deane NG, et al: Claudin-1 regulates cellular transformation and metastatic behavior in colon cancer. J Clin Invest 115: 1765-1776, 2005.

9. Morin PJ: Claudin proteins in human cancer: promising new targets for diagnosis and therapy. Cancer Res 65: 9603-9606, 2005.

10. Swisshelm K, Macek R and Kubbies M: Role of claudins in tumorigenesis. Adv Drug Deliv Rev 57: 919-928, 2005.

11. Japanese Society for Cancer of the Colon and Rectum. General Rules for Clinical and Pathological Studies on Cancer of the Colon, Rectum and Anus. 7th edition. Kanehara \& Co. Ltd., Tokyo, 2006

12. Sobin LH and Fleming ID: TNM classification of malignant tumors, fifth edition. Union Internationale Contre le Cancer and the American Joint Committee on Cancer. Cancer 80: 1803$1804,1997$.

13. Christensen TG, Burke B, Dexter DL and Zamcheck N: Ultrastructural evidence of dimethylformamide-induced differentiation of cultured human colon carcinoma cells. Increased expression of desmosomes. Cancer 56: 1559-1565, 1985.

14. Ishizu K, Sunose N, Yamazaki K, et al: Development and characterization of a model of liver metastasis using human colon cancer HCT-116 cells. Biol Pharm Bull 30: 1779-1783, 2007.

15. Aznavoorian S, Liotta LA and Kupchik HZ: Characteristics of invasive and noninvasive human colorectal adenocarcinoma cells. J Natl Cancer Inst 82: 1485-1492, 1990.

16. Mimori K, Mori M, Shiraishi T, et al: Clinical significance of tissue inhibitor of metalloproteinase expression in gastric carcinoma. Br J Cancer 76: 531-536, 1997.

17. Mori M, Staniunas RJ, Barnard GF, et al: The significance of carbonic anhydrase expression in human colorectal cancer. Gastroenterology 105: 820-826, 1993.

18. McCarthy KM, Skare IB, Stankewich MC, et al: Occludin is a functional component of the tight junction. J Cell Sci 109: 2287-2298, 1996.

19. Lui WY, Lee WM and Cheng CY: Transforming growth factorbeta3 perturbs the inter-Sertoli tight junction permeability barrier in vitro possibly mediated via its effects on occludin, zonula occludens-1, and claudin-11. Endocrinology 142 : $1865-1877,2001$

20. Mani SA, Guo W, Liao MJ, et al: The epithelial-mesenchymal transition generates cells with properties of stem cells. Cell 133 704-715, 2008

21. Hewitt KJ, Agarwal R and Morin PJ: The claudin gene family: expression in normal and neoplastic tissues. BMC Cancer 6: 186, 2006.

22. Higashi Y, Suzuki S, Sakaguchi T, et al: Loss of claudin-1 expression correlates with malignancy of hepatocellular carcinoma. J Surg Res 139: 68-76, 2007.

23. Leotlela PD, Wade MS, Duray PH, et al: Claudin-1 overexpression in melanoma is regulated by PKC and contributes to melanoma cell motility. Oncogene 26: 3846-3856, 2007.
24. Morohashi S, Kusumi T, Sato F, et al: Decreased expression of claudin-1 correlates with recurrence status in breast cancer. Int J Mol Med 20: 139-143, 2007.

25. Balkovetz DF: Claudins at the gate: determinants of renal epithelial tight junction paracellular permeability. Am J Physiol Renal Physiol 290: F572-F579, 2006.

26. Heiskala M, Peterson PA and Yang Y: The roles of claudin superfamily proteins in paracellular transport. Traffic 2: 93-98, 2001.

27. Furuse M, Sasaki H and Tsukita S: Manner of interaction of heterogeneous claudin species within and between tight junction strands. J Cell Biol 147: 891-903, 1999.

28. Andre T, Quinaux E, Louvet C, et al: Phase III study comparing a semimonthly with a monthly regimen of fluorouracil and leucovorin as adjuvant treatment for stage II and III colon cancer patients: final results of GERCOR C96.1. J Clin Oncol 25: 3732-3738, 2007.

29. Oku N, Sasabe E, Ueta E, et al: Tight junction protein claudin-1 enhances the invasive activity of oral squamous cell carcinoma cells by promoting cleavage of laminin-5 gamma2 chain via matrix metalloproteinase (MMP)-2 and membrane-type MMP-1. Cancer Res 66: 5251-5257, 2006.

30. Sheehan GM, Kallakury BV, Sheehan CE, et al: Loss of claudins- 1 and -7 and expression of claudins -3 and -4 correlate with prognostic variables in prostatic adenocarcinomas. Hum Pathol 38: 564-569, 2007.

31. Wolpin BM and Mayer RJ: Systemic treatment of colorectal cancer. Gastroenterology 134: 1296-1310, 2008.

32. Kornmann M, Formentini A, Ette C, et al: Prognostic factors influencing the survival of patients with colon cancer receiving adjuvant 5-FU treatment. Eur J Surg Oncol 34: 1316-1321, 2008.

33. Bathe OF, Dowden S, Sutherland F, et al: Phase II study of neoadjuvant 5-FU + leucovorin + CPT-11 in patients with resectable liver metastases from colorectal adenocarcinoma. BMC Cancer 4: 32, 2004

34. Iijima M, Kano Y, Nohno T and Namba M: Cloning of cDNA with possible transcription factor activity at the G1-S phase transition in human fibroblast cell lines. Acta Med Okayama 50: 73-77, 1996.

35. Hansen WJ, Cowan NJ and Welch WJ: Prefoldin-nascent chain complexes in the folding of cytoskeletal proteins. J Cell Biol 145: 265-277, 1999.

36. Hodgson G, Hager JH, Volik S, et al: Genome scanning with array $\mathrm{CGH}$ delineates regional alterations in mouse islet carcinomas. Nat Genet 29: 459-464, 2001

37. Lacy AM, Garcia-Valdecasas JC, Delgado S, et al: Laparoscopyassisted colectomy versus open colectomy for treatment of non-metastatic colon cancer: a randomised trial. Lancet 359: 2224-2229, 2002.

38. Weeks JC, Nelson H, Gelber S, et al: Short-term quality-of-life outcomes following laparoscopic-assisted colectomy vs open colectomy for colon cancer: a randomized trial. JAMA 287: 321-328, 2002.

39. Clinical Outcomes of Surgical Therapy Study Group: A comparison of laparoscopically assisted and open colectomy for colon cancer. N Engl J Med 350: 2050-2059, 2004.

40. Jayne DG, Guillou PJ, Thorpe H, et al: Randomized trial of laparoscopic-assisted resection of colorectal carcinoma: 3-year results of the UK MRC CLASICC Trial Group. J Clin Oncol 25: 3061-3068, 2007.

41. Koshariya M, Jagad RB, Kawamoto J, et al: An update and our experience with metastatic liver disease. Hepatogastroenterology 54: 2232-2239, 2007. 